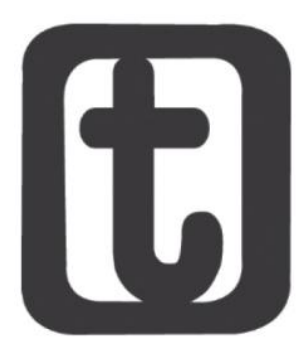

\title{
DIVISÃO SÓCIO SEXUAL DO TRABALHO: NATURALIZAÇÕES SOCIAIS COMO ESTRATÉGIA DE MINIMIZAÇÃO DO ESTADO
}

\author{
Socio-sexual division of labor: Social naturalization as a strategy for minimizing the \\ State
}

\author{
Priscilla Brandão Medeiros* \\ https://orcid.org/0000-0003-2183-6141
}

\section{RESUMO}

As mudanças no mundo do trabalho impactam na inserção de homens e mulheres no universo produtivo e reprodutivo o que faz perceber que há uma nítida e tradicional segregação quanto aos postos e condições de trabalho, mostrando, assim, uma desigualdade quanto às relações de gênero no que tange à ocupação dentro do universo do trabalho. Todavia, essa desigualdade não surge com o capitalismo, mas é nele que se intensifica, uma vez que é evidente como o trabalho feminino é satisfatório ao sistema produtivo, principalmente quando visto a naturalização da (in) visibilidade do trabalho reprodutivo, uma vez que não há por parte do Estado a proposição/elaboração de políticas sociais que garantam às mulheres a emancipação do seu lugar como normatizador junto à realização das atividades domésticas. É a partir desse anseio que o presente artigo se propõe a contribuir com o aprofundamento do debate acerca da divisão sócio sexual (e desigual) do trabalho em tempos de contrarreforma do Estado e, ainda, pensando em somar com a categoria dos/as assistentes sociais que é, majoritariamente, composta por mulheres. Como caminho metodológico, se caracteriza como uma pesquisa qualitativa e de cunho bibliográfica, a qual buscou aprofundar-se para que a essência do fenômeno estudado fosse revelada, sendo assim guiada pelo método crítico dialético. Portanto, é perceptível o quanto ainda é necessário o aprofundamento desse debate entre as categorias de gênero e classe (evidenciando a importância das questões de raça/etnia e orientação sexual), uma vez que a classe trabalhadora não é homogênea.

\section{PALAVRAS-CHAVE}

Divisão Sócio Sexual do Trabalho; Relações de Gênero; Capitalismo.

\section{ABSTRACT}

The changes in the world of work have an impact on the insertion of men and women in the productive and reproductive universe, which makes us realize that there is a clear and traditional segregation in terms of positions and working conditions, thus showing an inequality regarding gender relations in what regarding occupation within the universe of work. However, this inequality does not arise with capitalism, but it is where it intensifies, since it is evident how the female work is

\footnotetext{
* Assistente Social. Mestra em Serviço Social e Direitos Sociais. Doutoranda pelo Programa de Pós Graduação em Serviço Social pela Universidade Federal do Rio Grande do Norte. (UFRN, Natal, Brasil). Avenida Senador Salgado Filho, 3000, Lagoa Nova, Natal (RN), CEP.: 59078-970. E-mail: pbmo_4@hotmail.com.
}

\section{DOI 10.22422/temporalis.2020v20n40p215-232} Creative Commons Atribuição 4.0 Internacional (https://creativecommons.org/licenses/by/4.o/deed.pt BR), que permite copiar e redistribuir o material em qualquer suporte ou formato, bem como adaptar, transformar e criar a partir deste material para qualquer fim, mesmo que comercial. O licenciante não pode revogar estes direitos desde que você respeite os termos da licença. 
satisfactory to the productive system, especially when seen the naturalization of the (in) visibility of reproductive work, since it does not there is the proposition / elaboration of social policies by the State that guarantee women the emancipation of their place as a normatizer in the performance of domestic activities. It is from this desire that this article proposes to contribute to the deepening of the debate about the socio-sexual (and unequal) division of labor in times of counter-reform of the State and, still, thinking of adding to the category of social workers which is mostly made up of women. As a methodological path, it is characterized as a qualitative and bibliographical research, which sought to deepen so that the essence of the phenomenon studied was revealed, thus being guided by the critical dialectical method. Therefore, it is noticeable how much it is still necessary to deepen this debate between the categories of gender and class (highlighting the importance of issues of race / ethnicity and sexual orientation), since the working class is not homogeneous.

\section{KEYWORDS}

Socio-Sexual Division of Labor; Gender Relations; Capitalism.

\section{INTRODUÇÃO}

$\mathrm{O}$

presente artigo tem como propósito fomentar o debate acerca da divisão sócio sexual (e desigual) do trabalho a partir dos múltiplos contextos vivenciados pelas mulheres trabalhadoras e os reflexos da minimização do Estado frente à proposição de políticas públicas que tornem a sobrecarga de trabalho feminina amenizada. Diante do objetivo já é notório destacar o quanto é estratégico ao Estado Social a manutenção das construções/relações patriarcais de gênero, uma vez que não se torna necessário tal investimento nas políticas públicas, haja vista ser das mulheres a incumbência desse trabalho.

Assim sendo, a justificativa desse estudo se deu, inicialmente, pela aproximação da pesquisadora junto ao universo investigado, uma vez que tal realidade se configura cada vez mais assoladora no contexto contemporâneo e, por isso, já sentia o anseio de mergulhar e aprofundar teoricamente - buscando sair da aparência e entender a essência dos fenômenos - nas questões acerca das marcas do trabalho das mulheres e os reflexos na divisão sócio sexual do trabalho, haja vista ainda ser crescente a precarização nos postos de trabalho, o que vem chamando as mulheres - e todo o conjunto da classe trabalhadora - a (re) inventar seus cotidianos, de modo a buscar atender, basicamente, aos mínimos para garantir a sobrevivência.

No tocante ao caminho metodológico, a pesquisa foi guiada pelo método crítico dialético, por compreender que a realidade apresenta suas contradições e, para isso, partiu-se da aparência até a essência da realidade pesquisada, evidenciado os principais elementos que traduzem o real. Para isso, utilizou-se de estudos bibliográficos, com vieses marxistas, que trouxeram a possibilidade de maturação das hipóteses levantadas acerca da problemática destacada.

Dessa forma, é importante evidenciar que, historicamente, as mulheres estão inseridas nos postos de trabalho com menor prestígio social e, consequentemente, com menores remunerações. Isso leva a entender que o mundo do trabalho contemporâneo é caracterizado por uma desigualdade que transita desde o aspecto econômico e social até as relações sexistas.

Temporalis, Brasília (DF), ano 20, n. 40, p. 215-232, jul./dez. 2020. | ISSN 2238-1856 
Isso se dá por que, historicamente, há uma nítida e tradicional segregação quanto aos postos e condições de trabalho apresentadas aos homens e às mulheres, caracterizando, assim, uma desigualdade quanto às relações de gênero no que tange à ocupação dentro do universo de trabalho, como traz Bruschinni (2008) e Posthuma (1998). Configurou-se, então, uma divisão do trabalho calcada nas diferenças entre os sexos.

As mulheres sempre trabalharam, porém, na maioria das sociedades, elas trabalham mais que os homens e não tinham o reconhecimento no que se refere à realização de trabalho, além de salários mais baixos (CISNE, 2014) e, além disso, são as principais responsáveis pelas atribuições domésticas, fazendo com que seja cada vez menor seu tempo livre.

Contudo, para entender e analisar a divisão sexual do trabalho precisa-se ir além da simples verificação de desigualdades apontadas mediante a contradição sócio histórica, uma vez que é necessário mostrar que essas desigualdades são sistemáticas e articular essa realidade com o concreto, e perceber como tal divisão é satisfatória ao capital, haja vista a distância da proteção social enquanto garantia de estratégias que visem o atendimento das necessidades sociais coletivas que hoje são as mulheres que se responsabilizam.

Nesse sentido, é importante traçar caminhos que não apontem somente as constatações das desigualdades entre homens e mulheres e como essas são vistas em tempos de capitalismo, mas que possam compreender a origem do que envolve e desencadeia esse contexto, em um complexo dialético e de totalidade.

Portanto, é notória a relevância social e acadêmica que a pesquisa apresenta, uma vez que contribui com as análises da divisão sócio sexual (e desigual) do trabalho, podendo despertar a perspectiva crítica acerca desse recorte analítico; e academicamente, por ser o serviço social uma profissão majoritariamente composta e que tem como principal demanda mulheres e por ter seu projeto profissional pautado numa nova ordem societária.

\section{As marcas da exploração e precarização na vida das mulheres: o capital e a apropriação do trabalho feminino}

As discussões acerca da divisão social do trabalho se evidenciam em todo o processo histórico da humanidade. Para além dessa organização social do trabalho, os indivíduos se veem imersos em uma divisão deste que agrega condicionantes, como o gênero, raça e classe. A partir de determinado momento histórico, se configura uma fragmentação das tarefas para homens e mulheres, constituindo-se, assim, a divisão sócio sexual do trabalho.

A partir dos estudos de Nogueira (2006) tal divisão social e sexual já se encontra presente nos séculos que antecedem à Era Cristã, mas, é nas sociedades capitalistas que a divisão do trabalho se tornará limitada e alienada. 
A divisão do trabalho na indústria capitalista não é de modo algum idêntica ao fenômeno da distribuição de tarefas, ofícios ou especialidades da produção através da sociedade, porquanto, embora todas as sociedades conhecidas tenham dividido seu trabalho em especialidades produtivas, nenhuma sociedade antes do capitalismo subdividiu sistematicamente o trabalho de cada especialidade produtiva em operações limitadas (BRAVERMAN, 2011, p. 70).

Sobre isso, Nogueira (2006) vai analisar ainda que é na família que ocorrem as primeiras manifestações da divisão social e sexual do trabalho. Onde ela irá afirmar, calcada em Engels (2012), que a mulher e os (as) filhos (as), dentro do núcleo familiar, são encarados (as) com pessoas que estão para servir ao homem, na condição, principalmente, de esposo e pai, respectivamente.

[...] a família monogâmica é, em grande medida, um espaço manifesto de conflito entre homem e a mulher em consequência da opressão masculina, já que nessa esfera doméstica há um claro domínio patriarcal (NOGUEIRA, 2006, p. 23).

Para compreender os ditames que perpassam a opressão feminina quanto à divisão sócio sexual do trabalho "[...] a família [torna-se] uma importante chave para o entendimento histórico da exploração e opressão sobre as mulheres" (CISNE, 2014, p. 81). É nela que se fixam as bases tidas como naturais da submissão e precarização do trabalho da mulher, correspondendo ao sistema patriarcal.

Assim, percebe-se que a família, mesmo diante dos inúmeros avanços políticos, sociais acerca dessa instituição, continua como elemento importante para a reprodução do capital e das bases para sua apropriação, ou como diz Cisne (2014, p. 84) "[...] é um modo de circulação e de consumação de bens e serviços baseados na exploração da mulher".

Ou seja, é nesse espaço que se torna evidente o processo de (in) visibilização do trabalho realizado pelas mulheres, sendo este tido e tratado, historicamente como naturalizado à elas.

O aspecto mais importante da família na manutenção do domínio do capital sobre a sociedade é a perpetuação - e a internalização - do sistema de valores profundamente iníquo, que não permite contestar a autoridade do capital [...] (MÉSZÁROS, 2011, p. 271).

Ao longo das sociedades, as relações de gênero construídas foram determinando as tarefas, deveres e profissões para homens e mulheres, determinando, portanto, a divisão sexual do trabalho. As mulheres sempre trabalharam, porém, na maioria das sociedades, elas trabalham mais que os homens e não tinham o reconhecimento no que se refere à realização de trabalho, além de salários mais baixos (CISNE, 2014).

Segundo Hirata (2002, p. 280) "[...] a divisão sexual do trabalho é considerada como um aspecto da divisão social do trabalho, e nela a opressão/dominação está fortemente contida". 
Entender e analisar a divisão sócio sexual do trabalho precisa-se ir além da simples verificação de desigualdades apontadas mediante a contradição sócia histórica. Segundo a autora citada, é necessário mostrar que essas desigualdades são sistemáticas e articular as determinações que permeiam o real, para que se perceba a totalidade que as envolvem, sendo, portanto, importante traçar caminhos que não apontem somente as constatações dessas desigualdades entre homens e mulheres, mas que possam compreender a origem do que envolve e desencadeia esse contexto, em um complexo dialético e de totalidade.

Segundo Hirata; Kergoat (2008), a utilização do termo divisão sexual do trabalho surgiu em meados de 1970, na França, a partir do impulso do movimento feminista. Tornou-se evidente, neste período, numa perspectiva coletiva, que as mulheres realizavam uma enorme massa de trabalho de forma gratuita e invisibilizada pelo fato de ter sido naturalizado socialmente como atribuição direta das mulheres.

Foi então que, a partir dessas inquietações despertadas pelo movimento feminista francófano 1 e de mulheres que surgiram os primeiros estudos e discussões dentro das ciências sociais para tratar da divisão sexual do trabalho. Estes estudos evidenciaram a necessidade de se problematizar as atividades realizadas no âmbito doméstico como trabalho de mulheres e, trazer a reflexão que o mesmo deve ter seu estatuto modificado, devendo ser abordado como uma atividade profissional.

Sendo assim, partindo desse pressuposto sócio-histórico acerca dessa categoria, torna-se necessário trazer à tona a reflexão de como se deu o trabalho das mulheres historicamente, para assim, problematizar suas implicações.

A partir desse traço histórico, percebe que tanto a mulher livre quanto a mulher escravizada eram destinadas tarefas, na sua maioria, de cuidados dos (as) filhos (as) e a alimentação dos homens que iam para a caça e a pesca. Desde então, já ocorria uma divisão desigual das atividades, as quais se faziam perceptível à soberania do homem em relação à mulher e aos filhos (as).

$\mathrm{Na}$ Idade Média, as tarefas no trabalho em comunidade eram divididas por categorias entre as mulheres. Conforme Nogueira (2006):

[...] as solteiras eram responsáveis por lavar e tecer, as mães se ocupavam dos cuidados relativos às crianças pequenas e as mulheres de meia idade entretinham-se com as tarefas relacionadas com os adolescentes e com a cozinha, dentre outras atividades reprodutivas (NOGUEIRA, 2006, p. 24).

Neste instante, pode-se perceber que a análise da divisão sexual do trabalho passava de uma divisão de uma relação de gênero para, também, uma relação de classe, uma vez que as mulheres dos camponeses e dos servos trabalhavam de forma mais acentuada do que as mulheres burguesas. Ainda segundo Nogueira (2006), as primeiras além de trabalhar na agricultura, cuidar dos filhos (as) e do lar,

\footnotetext{
${ }^{1} \mathrm{O}$ movimento francófano surge na França, de forma mais acentuada no século XIX, a partir de uma linha radical, apoiadas na perspectiva crítica dialética.
} 


\section{temporalis}

muitas vezes, eram as amas dos filhos (as) das burguesas. Entende-se, com isso, que a intensa jornada de trabalho da mulher já existe há séculos.

Já na Idade Moderna, apesar da mulher adentrar o mundo fabril, por necessidade do capital, ela não abandonaria os afazeres domésticos, em virtude do cuidado do lar e dos filhos. Para Gama (2014), o cuidado é concebido "[...] como uma atividade feminina geralmente não remunerada, sem reconhecimento nem valorização social" (GAMA, 2014, p. 47).

É importante destacar que essa emancipação do trabalho doméstico, de fato, não aconteceu, mas, mudou sua configuração. Com a entrada massiva da mulher no mundo do trabalho produtivo ocorreu à transferência da atribuição das atividades domésticas para outras mulheres, em parte, quando pensando a realidade das mulheres burguesas. Mostrando então, que o trabalho doméstico continua como encargo feminino. Tal constatação é evidenciada no que traz Sorj (2004) quando faz uma análise da marca social, histórica e cultural que as mulheres carregam no tocante a responsabilização com a família. Em pesquisa realizada para analisar como se dava a divisão sexual do trabalho na esfera doméstica, a autora apresenta que:

[...] em 96\% dos domicílios pesquisados, a principal responsável pelas tarefas domésticas era uma mulher. Além disso, quando outra pessoa participava das responsabilidades pelo trabalho doméstico, em $49 \%$ dos casos tratava-se também de uma mulher (SORJ, 2004, p. 112).

E ainda sob essa análise, recai o viés de raça e classe, uma vez que são as mulheres, na maioria, negras e pobres, que ocuparão a função do cuidado doméstico do lar das famílias de classe média, sendo esse fenômeno caracterizado pelo "princípio da delegação e da conciliação" do trabalho reprodutivo de uma mulher para outra como aponta Hirata; Kergoat (2007), agora fincado numa lógica remunerada trabalho assalariado -, destinando a articulação entre o trabalho e a vida familiar.

No geral, ao adentrar a esfera do trabalho assalariado, na condição de trabalhadora doméstica, assume essa jornada de trabalho mais exaustiva, por cuidar do seu lar e filhos (as) e trabalhar fora de casa, muitas vezes, como babá e/ou empregada doméstica.

Para as mulheres o quadro de precarização e exploração será ainda mais acentuado, uma vez que as mesmas assumirão uma jornada de trabalho mais intensa por continuar o trabalho doméstico.

E mais, quando há uma comparação da divisão das tarefas domésticas entre homens e mulheres, os dados comprovam que permanece como sendo das mulheres a responsabilidade pela sua execução, mesmo que os homens, minimamente, se incluam nestas. Para evidenciar esse aspecto, segundo Cisne (2014), com base em uma pesquisa realizada pela Pesquisa Nacional por Amostra de Domicílios (PNAD) - do Instituto Brasileiro de Geografia e Estatística (IBGE) - em 2011, é evidente que continua mínima a participação masculina na realização das tarefas domésticas quando comparada com os dados de 2001. 
Segundo o resultado da pesquisa, os homens ocupados dedicavam dez horas semanais com os afazeres domésticos em 2001. Em 2011, esse dado aumenta somente oito minutos, ou seja, dez horas e oito minutos do tempo que um homem empregado no Brasil dedica às atividades domésticas, enquanto as mulheres ocupadas destinavam vinte e quatro horas e quatro minutos no início da década passada. Em 2011, a atividade consumia vinte e duas horas e treze minutos. Esses dados revelam, portanto, que embora o avanço das forças produtivas tenha diminuído o trabalho doméstico feminino, ainda estamos longe de vê-lo eliminado (CISNE, 2014, p. 84-85).

É notório que historicamente as análises acerca das esferas produtiva e reprodutiva constituíram fator importante para compreender a submissão das mulheres e a hierarquização das ocupações e funções destinados a ambas as categorias, uma vez que é notório, como já apontado anteriormente, a marca sócio histórica da destinação feminina às responsabilizações com o trabalho reprodutivo.

[...] a divisão entre esfera produtiva e reprodutiva fortaleceu a hierarquia e a desigualdade entre homens e mulheres. A esfera produtiva é a da valorização, da produção da riqueza e, portanto, é tida como um espaço privilegiadamente masculino. A esfera da reprodução social - aqui entendida como as atividades necessárias para garantir a manutenção e reprodução da força de trabalho -, é considerada um espaço feminino (CISNE, 2014, p. 88).

Essa divisão entre o produtivo/reprodutivo, apontada pela autora supramencionada, fez eclodir, em determinados momentos históricos, atitudes de resistência dos homens às mulheres no espaço de trabalho industrial. Visão machista e justificada pelo intrínseco preconceito oriundo da naturalização de que a mulher é destinada ao trabalho doméstico e a visão, socialmente construída, quanto à secundarização feminina.

No entanto, algumas mulheres, nas suas tentativas de ingressarem nas fábricas, ainda tem sua força de trabalho recusada pelos homens em virtude do preconceito, fazendo com que elas se voltassem para o espaço do trabalho doméstico, especialmente trabalhando nas casas de outras mulheres pertencentes à burguesia (NOGUEIRA, 2006, p. 24-25).

Muitas das discussões sobre a não-aceitação da mulher no mercado de trabalho deram-se pela não combinação entre o trabalho produtivo e reprodutivo. Pois questionavam, que as mesmas não iriam cuidar e educar, de maneira correta, os (as) filhos (as).

Portanto, foi se concretizando as condições sociais que legitimavam a precarização e subjugação da vida das mulheres, constituindo o contexto para uma força de trabalho pronta a ser explorada pelo capital.

As desvantagens sociais de que gozam os elementos do sexo feminino permitiam à sociedade capitalista em formação arrancar das mulheres o máximo de mais-valia absoluta através, simultaneamente, da intensificação do trabalho, da extensão da jornada de trabalho e de salários mais baixos que os masculinos, uma vez que, para o processo de 
acumulação rápida de capital, era insuficiente a mais-valia relativa obtida através do emprego da tecnologia de então (SAFFIOTI, 2013, p. 67).

Essa inserção ocorreu diante de um cenário econômico e social marcado pela crise que afetou os Estados capitalistas - em especial os países centrais. As condições de trabalho se deterioraram, em níveis desiguais pelo mundo. Homens e mulheres vivenciaram contextos diferentes, uma vez que o desemprego estrutural se fazia presente e foi elemento novo neste período, assim como a necessidade de modificações na legislação trabalhista e outros direitos sociais.

Refletindo sob o recorte de classe, gênero e raça - uma vez que mesmo não analisando profundamente o viés da raça, ele torna-se visível em suas problematizações -, Antunes (2000, p. 105-106) traz a discussão em torno da divisão sexual do trabalho no espaço fabril e apresenta as particularidades que circunscrevem a ocupação de homens e de mulheres.

Na divisão sexual do trabalho, operada pelo capital dentro do espaço fabril, geralmente as atividades de concepção ou aqueles baseadas em capital intensivo são preenchidas pelo trabalho masculino, enquanto aquelas dotadas de menor qualificação, mais elementares e muitas vezes fundadas em trabalho intensivo, são destinadas as mulheres trabalhadoras (e, muito frequentemente também aos trabalhadores/as imigrantes e negros/as) (ANTUNES, 2000, p. 105-106).

A globalização ou mundialização da economia propiciou ao capitalismo enfrentar a crise e levou a uma acumulação sem fronteiras, com consequências múltiplas para todos os (as) trabalhadores (as), principalmente para as mulheres. Para sustentar esta acumulação do capital, foi implementado mundialmente, de forma especifica em cada localidade, um conjunto de medidas que modificaram as formas de organização e gestão do trabalho, consubstanciando "novas" bases do sistema de produção, com impactos diversos para a produção e os (as) trabalhadores (as). A reestruturação produtiva trouxe (traz) elementos para aperfeiçoamento da produção e extração de valor e manutenção do status quo do capital.

[...] essa intensificação é também resultado dos novos modelos, das novas formas de organização do trabalho e da produção. Estas novas formas são organizações flexíveis da produção e aparecem como extremamente essenciais para a própria reprodução do sistema de trabalho e do emprego (HIRATA, 2010, p. 23).

Neste contexto, abordar as relações de trabalho que estão inseridas as mulheres é pensar em precarização e exploração quanto ao uso de sua força de trabalho, uma vez que, à luz do capital, a categoria trabalho tem seu sentido ontológico (des) construído. Contudo, as metamorfoses que afetam o mundo do trabalho contemporâneo apontam repensar a divisão sócio sexual do trabalho para que seu entendimento, fincado numa perspectiva crítica, possa romper com as naturalização das desigualdades neste, indo ao encontro da essência que envolve suas determinações. 
É, portanto, diante da construção crítica do debate acerca da divisão sexual do trabalho que as autoras Hirata e Kergoat (2008) definem este conceito, partindo do entendimento de que:

A divisão sexual do trabalho é a forma de divisão do trabalho social
decorrente das relações sociais entre os sexos; mais do que isso, é um
fator prioritário para a sobrevivência da relação social entre os sexos. Essa
forma é modulada histórica e societalmente. Tem como características a
designação prioritária dos homens à esfera produtiva e das mulheres à
esfera reprodutiva e, simultaneamente, a apropriação pelos homens das
funções com maior valor social adicionado (políticos, religiosos, militares,
etc.) (HIRATA; KERGOAT, 2008, p. 266).

Para além dessa constatação, Hirata e Kergoat ainda apontam elementos para uma compreensão mais detalhada que envolve a divisão sexual do trabalho. As mesmas discorrem que essa maneira de tratar a divisão social do trabalho em bases sexistas tem princípios organizadores - o da separação e o hierárquico.

O primeiro problematiza a definição de que existem trabalhos de homens e trabalhos de mulheres, a partir das naturalizações e caracterizações, socialmente construídas, de que os espaços são definidos e, consequentemente, ocupados mediante uma análise a partir do sexo, consubstanciados mediante as construções de gênero.

Segundo apontamentos das autoras Pelatieri e Lima (2008, p. 139), “[...] as mulheres ainda ingressam no mercado de trabalho em situação desigual, se comparada à dos homens, e esta desigualdade permanece durante toda sua trajetória".

Tal constatação torna-se ainda mais acentuada quando se adentra na análise de classe, uma vez que "historicamente, são as mais pobres que se encontram em condições de trabalho mais precárias, estão sujeitas à violência, têm menos acesso à formação profissional e técnica [...]” (PELATIERI e LIMA, 2008, p. 141).

O quadro de inserção em postos precários e com críticas condições de valorização do trabalho permeia o contexto de vida das mulheres quando visto a partir das ocupações no mundo do trabalho. Diante disso, Cisne (2014) assevera que:

A divisão sexual do trabalho, por conseguinte, não pode ser compreendida apenas como uma diferença entre os trabalhos realizados por homens e mulheres e sim como a base das assimetrias e hierarquias contidas nessa divisão, e que se expressam nas desigualdades existentes, dentre outros aspectos, nas carreiras, nas qualificações e nos salários entre os sexos (CISNE, 2014, p. 89).

$E$, mesmo estando às mulheres inseridas em espaços com condições de trabalho mais satisfatórias, ainda é percebível a continuidade de sua participação em atividades que fixam as naturalizações socialmente atribuídas a elas. Isso se mostra evidente a partir dos estudos apontados por Hirata (2002) quando a mesma aborda que: 
À divisão das oficinas de acordo com o sexo correspondiam diferenças nos tipos de tarefas. As mulheres efetuavam trabalhos de montagem leves, sob forte pressão de tempo e um ritmo de trabalho imposto, seja por uma linha de montagem, seja pela supervisão dos chefes. Trabalhos simples, dissociados, fragmentados, que realizavam sentadas, com as mãos ou pequenas ferramentas, em um ambiente, sobretudo limpo e tranquilo (HIRATA, 2002, p. 179).

Corroborando com o pensamento de Hirata (2002), Cisne (2014) diz que:

A apropriação dessas 'qualidades' tidas como femininas desconsidera o treinamento informal das mulheres, atribuindo tais 'qualidades' a uma suposta 'natureza feminina'. Isso permite que as atividades realizadas pelas mulheres não sejam percebidas, tampouco, valorizadas como um trabalho especializado, o que serve de justificativa para os baixos salários (CISNE, 2014, p. 91).

Ou seja, a naturalização do processo sócio-histórico em tempos de capitalismo - e principalmente após o neoliberalismo - findam por concretizar esse lugar que a mulher deve ocupar, e para isso, alinha o modelo de educação sexista que baliza essa realidade.

O segundo elemento que possibilita uma análise mais apropriada da divisão sexual do trabalho é o hierárquico, que se refere, segundo Hirata e Kergoat (2008), as construções hierárquicas de que o trabalho do homem "vale" mais do que o trabalho realizado pela mulher. Esse destaque é relevante uma vez que ainda é notório o distanciamento entre a remuneração recebida pelas mulheres em relação a dos homens, mesmo quando ocupando o mesmo cargo de trabalho.

A atividade econômica feminina continua sendo caracterizada por segregação ocupacional, em setores de baixos status, com remuneração menor que os homens, mesmo quando elas exercem a mesma carga horária e têm níveis equivalentes de escolaridade (POSTHUMA, 1998, p. 21).

Além disso, "[...] a expansão do trabalho feminino tem se verificado, sobretudo no trabalho mais precarizado [...] com desníveis salariais ainda mais acentuados em relação aos homens" (ANTUNES, 2000, p. 108).

Compreender a divisão sexual do trabalho implica, ainda, problematizar os aspectos em torno das dimensões de classe, uma vez que:

As relações entre gênero e classe nos permitem constatar que, no universo do mundo produtivo e reprodutivo, vivenciamos também a efetivação de uma construção social sexuada, onde os homens e as mulheres que trabalham são, desde a família e a escola, diferentemente qualificados e capacitados para o ingresso no mercado de trabalho. E o capitalismo tem sabido apropriar-se desigualmente dessa divisão sexual do trabalho (ANTUNES, 2000, p. 109). 
É inegável a compreensão de que a categoria gênero não se resume a entender as relações sociais unicamente pela perspectiva do sexo, mas, numa perspectiva de totalidade, que compreende as construções sociais vivenciadas em sociedade. A lógica binária de que o lugar do homem é assumindo o papel do trabalho na esfera pública e a mulher na esfera privada vai perdurar e se agravar no sistema capitalista.

Na contemporaneidade se apresentam múltiplas facetas e cenários oriundos das transformações no mundo do trabalho guiadas pelo interesse do capital, que Antunes (2005) vai chamar de "nova morfologia do trabalho". São as novas determinações que caracterizam o contexto da classe trabalhadora.

[...] uma noção ampliada, abrangente e contemporânea de classe trabalhadora, hoje, a classe-que-vive-do-trabalho, deve incorporar também aqueles e aquelas que vendem sua força de trabalho em troca de salário, como o enorme leque de trabalhadores precarizados, terceirizados, fabris e de serviços, part-time, que se caracterizam pelo vínculo de trabalho temporário, pelo trabalho precarizado, em expansão na totalidade do mundo produtivo (ANTUNES, 2005, p. 52).

As estratégias usadas pelo capital para obter seus interesses lucrativos, vão na direção das mais perversas formas de precarização e alienação da força de trabalho humana. Em meio a esse cenário, as mulheres aparecem como parte integrante do universo dos trabalhadores, enquanto sujeitos imersos na categoria de assalariados $^{2}$.

Para caracterizar o universo do trabalho atual em que se inserem as mulheres é importante perceber que a classe trabalhadora não é um todo homogêneo, muito pelo contrário. A referida classe tem caráter heterogêneo, quando vista pela órbita de que homens e mulheres são vistos e assumem condições diferenciadas na esfera de mercado.

\begin{abstract}
As tradições de masculinização e feminização de profissões e tarefas se constituem às vezes por extensão de práticas masculinas e femininas: homens fazem trabalhos que exigem força, mulheres fazem trabalhos que reproduzem tarefas domésticas. Mas, mais do que a transferência das tarefas, são as regras da dominação de gênero que se produzem e reproduzem nas várias esferas da atividade social (LOBO, 1991, 152).
\end{abstract}

Mesmo considerando o avanço no que se refere ao ingresso das mulheres na esfera pública ${ }^{3}$, tanto em nível de Brasil como de mundo, é preciso reconhecer que não há uma situação democrática no que tange às condições de sua permanência no mercado de trabalho. Permanecessem as assimetrias em relação aos direitos

\footnotetext{
2 “Tal organização da produção, ao reduzir o uso da força muscular, permite a ampliação do contingente disponível dos assalariados mediante a incorporação do trabalho da mulher e da criança, e coloca toda a família trabalhadora sob a dependência do capital” (IAMAMOTO, 2008, p. 73).

${ }^{3}$ A conquista do espaço produtivo se deve ao protagonismo do movimento feminista, que contribuiu para a construção da perspectiva revolucionária, crítica e política das mulheres. Este movimento de luta levantou bandeiras que tinham um teor de inquietar, questionar e problematizar a condição e a posição social, política, econômica e cultural em que a mulher ocupava.
}

Temporalis, Brasília (DF), ano 20, n. 40, p. 215-232, jul./dez. 2020. | ISSN 2238-1856 
trabalhistas em comparação com os homens e pouco se conquistou no âmbito da esfera doméstica, já que esta continua sendo atribuição feminina.

\begin{abstract}
A entrada em massa das mulheres na força de trabalho no século 20, em extensão tão significativa que hoje elas já chegam a constituir maioria nos países de capitalismo avançado, não resultou em sua emancipação. Em vez disso, apareceu a tendência de generalizar para toda a força de trabalho a imposição dos salários mais baixos a que as mulheres sempre tiveram de se submeter; exatamente como a 'concessão' legislativa à mulheres [...] (MÉSZÁROS, 2011, p. 272).
\end{abstract}

Assim, a conciliação entre o produtivo e reprodutivo acarretou para as mulheres, como já discorrido antes, uma intensificação de sua jornada de trabalho.

O capital, no entanto, veio a se apropriar das "qualidades" e atributos ditos femininos como estratégia mercadológica para explorar sua força de trabalho, tanto na esfera reprodutiva, já que este se constitui como indispensável para a reprodução da força de trabalho, como também para a garantia da produção de mercadorias. Entretanto, a parte do trabalho realizado pelas mulheres no espaço privado fica a margem do mercado.

A sociedade valoriza o trabalho destinado ao mercado, relegando a um segundo plano o trabalho não-mercantil. Desse modo, o trabalho reprodutivo, sempre visto como preferencialmente de responsabilidade das mulheres, não é computado na jornada de trabalho (PELATIERI; LIMA, 2008, p. 137).

Assim, a mulher é duplamente explorada salarialmente, pois recebe sempre menos que os homens e nunca é paga pelas atividades que realiza no âmbito doméstico.

Os contornos da nova morfologia do trabalho mostram que as mulheres estão se inserindo em atividades formais precarizadas, repetitivas, com pouca tecnologia, com baixos salários, e, por outro lado, é maioria no mercado informal de trabalho. Este cenário se configura nas naturalizações orientadas perante o recorte de gênero.

\begin{abstract}
Como se pode verificar facilmente nas cidades produtivas nacionais e internacionais, as mulheres predominam nos estágios mais degradados da terceirização ou quarterização. A Nike, por exemplo, usa mão-de-obra feminina oriental, trabalhando em domicílio e recebendo quantias miseráveis. Todos os estudos sobre força de trabalho feminina no mundo de economia globalizada revelam sua mais acentuada subordinação. Isto equivale a dizer que, quanto mais sofisticado o método de exploração praticado pelo capital, mais profundamente se vale da dominação de gênero de que as mulheres já eram, e continuam sendo, vítimas (SAFIOTTI, 2004, p. 129-130).
\end{abstract}

As novas formas de contratação de pessoal possibilitam a mulher assumir determinadas atividades que agudizam sua exploração e prejudicam seu desenvolvimento. 
Sobre essas novas formas de trabalho, Antunes (2013) aponta que o mundo do trabalho contemporâneo, mediante as tranformações sociais e econômicas pós década de 1970, apresenta um nítido sentido multiforme, o qual afetará, consubstancialmente, a classe trabalhadora.

[...] as novas formas vigentes de valorização do trabalho, ao mesmo tempo que trazem embutidos novos mecanismos geradores de trabalho excedente, precarizam, informalizam e expulsam da produção uma infinitude de trabalhadores [e trabalhadoras] que se tornam sobrantes, descartáveis e desempregados (ANTUNES, 2013, p. 13).

As transformações no mundo trabalho impactaram nas múltiplas formas de trabalho, onde de um lado temos a exigência de força de trabalho intelectualizada para inserção em postos de trabalho dotados de informatização e tecnologia e, de outro, assistimos aos diversos modos da informalidade, como: o trabalho terceirizado (caracterizando o retorno de bases arcaicas de produção nas células familiares, por exemplo), o incentivo ao trabalho voluntário, o cooperativismo.

Esse cenário estratégico beneficiará diretamente o capital, uma vez que o montante de trabalhadores/as sobrantes no mercado de trabalho e sujeitos a essas formas de empregabilidade redundará na criação do que Antunes (2013) chama de "bolsão de desempregados".

O reflexo será a diminuição na redução da remuneração dos trabalhadores/as, distanciamento do acesso aos direitos trabalhistas e um acirramento na busca de inserção e permanência no mercado de trabalho.

Quando o Estado de Bem Estar Social traz, na contemporaneidade a provisão da proteção social, esse não incluiu as necessidades de acessos aos direitos por parte das mulheres.

[...] as feministas argumentam que esse conjunto de direitos é insuficiente para indicar o nível de proteção social da sociedade, justamente porque são benefícios destinados ao trabalhador assalariado (produtivo), que geralmente é um trabalhador masculino. Além disso, o trabalho reprodutivo e o universo das famílias permanecem ignorados (SORJ e FONTES; 2012, p. 60).

É contundente o quanto o conflito trabalho - família é notório na vida de milhares de mulheres, uma vez que o desenho das políticas sociais não visam a superação da marca histórica da inserção naturalizada das mulheres como responsáveis natas pelos cuidados domésticos, ou seja, pela forma de trabalho reprodutivo que serve ao capital e que, para elas, custam o dispêndio de horas de trabalho não remunerado. Gama (2014, p. 95) deixa isso claro quando traz que "[...] o Estado sistematicamente estruturou a provisão de bem-estar social por meio do trabalho 'invisível' da mulher. Desde então, as críticas às políticas sociais têm-se ampliado e sustentado". 
A proteção social trazida pelo Estado é entendida, então, como de cunho transversal com as questões de gênero, haja vista não se compreender que as mulheres gozam dos mesmos direitos sociais e, consequentemente, o mesmo alcance da cidadania. Cabendo assim questionar: como pensar a cidadania feminina? Como as mulheres (mães, especialmente) podem almejar a inserção/permanência no mercado de trabalho? Por quê o trabalho reprodutivo continua como responsabilização (in) visível das mulheres?

O salário é o traço característico da cidadania moderna, pois ele garante autonomia, o que significa que as mulheres correm o risco de serem cidadãs de segunda classe quando trabalham em tempo parcial ou quando permanecem na inatividade para cuidar dos filhos pequenos, dos idosos e dos doentes (GAMA, 2014, 98).

E acrescentando com as ideias de Marx (2006, p. 35)

[...] salário é apenas um nome especial dado ao preço da força de trabalho, a que se costuma chamar preço do trabalho; é apenas o nome dado ao preço dessa mercadoria particular que só existe na carne e no sangue do homem [mulher] (MARX, 2006, p. 35).

O que se traz para o debate é exatamente a reflexão acerca da estruturação de políticas sociais que garantam as mulheres sua emancipação da esfera reprodutiva como traço direto do sistema de gênero - nasci mulher, sou responsável pelos cuidados do lar -. O que evidencia é justamente a criação de creches integrais que atendam as demandas reais, lavanderias públicas, restaurantes populares, como apresenta Cisne (2014).

Todas as políticas públicas, e de maneira ainda mais enfática as políticas sociais, contêm implícita ou explicitamente alguma concepção de gênero. Uma vez que o gênero é um princípio central que organiza relações de desigualdade na sociedade e constitui as pessoas como diferentes, as políticas públicas incidem, direta ou indiretamente, sobre as relações entre homens e mulheres, seja mantendo, corrigindo ou acentuando as desigualdades existentes (SORJ e FONTES, 2012, p. 57).

Assim, percebe-se que, historicamente, o trabalho de cuidados é uma atribuição socialmente naturalizada às mulheres, como condicionante ainda maior após assumirem os vínculos contratuais com o casamento. Dessa forma, tem-se a responsabilização direta das mulheres com todo o envolto que perpassa a atenção aos cuidados, tornando esse assunto algo privativo ao ser feminino, situação ainda mais agravada no Brasil quando vimos essa "timidez" nas políticas públicas especialmente as sociais - que venha dá suporte a essa intensificação da jornada de trabalho das mulheres, como traz Sorj na passagem supramencionada.

Mas, o que se observa é a concepção fundamentalista da direção da proteção social da família por parte do Estado, baseada na fixação das construções sociais conservadoras. É importante entender que esse lugar exigido às mulheres tem total interesse do Estado, que é neoliberal e capitalista, uma vez que o papel feminino na provisão do bem estar social é consequência direta para manutenção da

Temporalis, Brasília (DF), ano 20, n. 40, p. 215-232, jul./dez. 2020. | ISSN 2238-1856 
reprodução social e da geração da mais valia, sem precisar, portanto, que esse Estado se responsabilize por tais questões, pois já há uma direção social que coloca pessoas nessa destinação.

Assim, é notório que são as mulheres as principais responsabilizadas pelo trato e "cuidado" com o que envolve a esfera reprodutiva e tudo que é extensão destas, evidenciando que essa determinação da divisão sexual do trabalho, que é patriarcal também, imputa "[...] às mulheres uma responsabilização sobre as expressões da questão social” (CISNE; SANTOS, 2018, p. 151).

Isso fortalecido no modelo de educação sexista, e aí não distante desse modelo de Estado Mínimo, mas pelo contrário, como parte de sua proposta de colocar o trabalho feminino como atendimento gratuito as necessidades sociais coletivas.

\begin{abstract}
O sistema patriarcal - racista - capitalista não mede esforços desenvolver uma ideologia que naturaliza o 'papel' da mulher na sociedade por meio de uma cultura e educação sexista que fomenta que ser mulher é sinônimo de sacrifício e doação ao outro, ainda que em detrimento de si, dos seus desejos, das suas necessidades e do seu tempo (CISNE; SANTOS, 2018, p. 151-152).
\end{abstract}

Ou seja, cabem às mulheres corresponder com a manutenção social, não "somente" no atendimento as exigências com o trabalho doméstico, mas cuidados com filhos e entes dependentes, e mais, com o ambiente externo quando visto que essa direção sexista e os papéis cobrados a assumir, coloca também o controle dos conflitos sociais. Dessa forma, é totalmente funcional ao Estado esse modelo patriarcal que é funcional aos seus interesses, quando se vê essa cobrança das mulheres como responsáveis pela amenização desses conflitos junto à classe trabalhadora, atribuindo um viés moralizador na formação como ser social, negando e rejeitando a sua inserção nos espaços de articulação e construção política, exatamente por que as mulheres findam praticamente sem tempo livre e disso decorre em menos condições para a inserção em formação profissional e nesses espaços de militância.

Portanto, são as mulheres que vivenciam as jornadas de trabalho mais intensas e a inserção em vínculos mais precários, ou seja: “[...] as atividades de trabalho das mulheres constituem uma jornada de trabalho extensiva, intensiva e intermitente. Ou seja, há um continuum do trabalho das mulheres que se insere em uma única lógica de exploração: a do sistema heteropatriarcal - racista - capitalista" (CISNE; SANTOS, 2018, p. 159).

Assim, evidencia-se a importância do feminismo para a luta emancipatória das mulheres e como práxis social que permita às mulheres refletir, e mais, por entender a necessidade da organização política como ferramenta de romper com esse cotidiano assolador que naturaliza os espaços e a condição das mulheres socialmente.

[...] todos os fatos históricos e as últimas descobertas antropológicas nos levam a afirmar que existiu um período de humanidade no qual havia 
igualdade entre a mulher e o homem, e é justamente o período no qual ambos tinham uma relação orgânica com seus pressupostos de trabalho (TOLEDO, 2005, p. 25).

Contudo, é importante compreender que o capitalismo trata de naturalizar a desigualdade entre homens e mulheres como uma estratégia própria deste sistema. Implicando as relações sociais de gênero, classe e raça em condicionamentos fundantes desta lógica impregnada no tecido social, fazendo dos seres humanos "marionetes" da sociedade burguesa.

\section{CONSIDERAÇÕES FINAIS}

Diante do processo que caracteriza a divisão sócio sexual do trabalho, nos deparamos diariamente com mulheres que vivem de maneira desigual aos homens que também estão inseridos no mercado de trabalho -, pois, a partir das observações feitas com base nos estudos, foi visto que todas as mulheres recebem os salários mais baixos e que, hegemonicamente, ainda são elas (ou nós, na condição de ser mulher) as principais responsáveis pelas atribuições domésticas, o traz como consequência a redução ou ausência de tempo livre para se dedicar a qualquer outra atividade, como a qualificação profissional, por exemplo.

Dessa forma, fica claro que o Estado não garante, de fato, uma proteção social às mulheres, quando visto as análises das construções sociais de gênero e, fica notório ainda a ausência das políticas públicas com esse segmento, uma vez que não se percebe, quando analisadas as pesquisas, que isso se constata como pauta política na conjuntura estatal.

Assim, a estratégia do capital de aumentar a sua mais-valia, com a utilização da força de trabalho das mulheres em atividades que exploram as qualidades ditas femininas vem sendo usada com sucesso. É importante, porém, relembrar que as diferenças existentes entre o homem e a mulher não impedem que possam desenvolver qualquer atividade ou ocupar qualquer lugar na esfera social. São capazes de assumir atividades diversas na sociedade, desde que tenham as mesmas oportunidades. Na atual realidade da divisão sexual do trabalho, o que se tem são signos socialmente construídos e que justificam tratamentos diferenciados, com privilégios para os homens e exclusão para as mulheres.

E essa realidade torna o cotidiano do segmento feminino marcado por construções que perduram séculos, sendo evidente a direção política na pauta cotidiana na busca emancipatória e mesmo na percepção como sujeitas dotadas de direitos, os quais quando não são inexistentes, são violados e/ou negados.

Portanto, para falar das desigualdades sociais que perpassam as vidas das mulheres é necessário se debruçar acerca das especificidades que envolvem as estratégias do capitalismo e do patriarcado, entendendo como este se apropria disso para garantia de ideários na reprodução indireta da mais valia a partir do trabalho não remunerado - mas necessário a manutenção social - desenvolvido pelas mulheres,

Temporalis, Brasília (DF), ano 20, n. 40, p. 215-232, jul./dez. 2020. | ISSN 2238-1856 
como ainda, o interesse em (re) produzir uma cultura de ausência do Estado no tocante a criação/ampliação de políticas públicas que visem as análises sob os recortes de gênero, pois como já defendido no decorrer desse estudo, são visíveis os motivos que exigem essa atualização da agenda dos movimentos sociais - tarefa que o movimento feminista já "grita" há décadas - e principalmente, na direção de perceber a proteção social em sua totalidade.

\section{REFERÊNCIAS}

ANTUNES, Ricardo. O caracol e a concha: ensaios sobre a nova morfologia do trabalho. São Paulo: Boitempo, 2005.

ANTUNES, Ricardo (org.). Os sentidos do trabalho: ensaios sobre a afirmação e a negação do trabalho. 2. ed. São Paulo: Boitempo, 2000.

ANTUNES, Ricardo. A nova nova morfologia do trabalho e suas principais tendências. In: ANTUNES, Ricardo. (org.). Riqueza e miséria do trabalho no Brasil II. São Paulo: Boitempo, 2013.

BRAVERMAN, Harry. Trabalho e capital monopolista: a degradação do trabalho no Século XX. Rio de Janeiro: LTC, 2011.

BRUSCHINI, Cristina. Trabalho e gênero no Brasil até 2005: uma comparação regional. In: BRUSCHINI, Cristina et al (org.). Mercado de trabalho e gênero: comparações internacionais. Rio de Janeiro: Editora FGV, 2008.

CISNE, Mirla; SANTOS, Silvana Mara. Feminismo, diversidade sexual e serviço social. São Paulo: Cortez, 2018.

CISNE, Mirla. Feminismo e consciência de classe no Brasil. São Paulo: Cortez, 2014.

ENGELS, Friedrich. A origem da família, da propriedade privada e do Estado; tradução Leandro Konder - $3^{\mathrm{a}}$ ed. São Paulo: Expressão Popular, 2012.

GAMA, Andréa de Souza. Trabalho, família e gênero: impactos dos direitos do trabalho e da educação infantil. São Paulo: Cortez, 2014.

HIRATA, Helena. Crise mundial e o impacto da reestruturação produtiva na divisão sexual do trabalho. In: COSTA, Albertina; ÁVILA, Maria Betânia de Melo (org.).

Divisão sexual do trabalho, Estado e crise do capitalismo. Recife: SOS CORPO, 2010.

HIRATA, Helena. Nova divisão sexual do trabalho? Um olhar voltado para a empresa e para a sociedade. São Paulo: Boitempo, 2002.

HIRATA, Helena; KERGOAT, Daniéle. Divisão sexual do trabalho profissional e doméstico: Brasil, França e Japão. In: BRUSCHINI, Cristina et al (org.). Mercado de trabalho e gênero: comparações internacionais. Rio de Janeiro: Editora FGV, 2008.

HIRATA, Helena; KERGOAT, Daniéle. Novas configurações da divisão sexual do trabalho. Cadernos de Pesquisa, v. 37. n. 132, p. 595 - 609. set./dez. 2007. 
IAMAMOTO, Marilda Villela. Serviço Social em tempo de capital fetiche: capital financeiro, trabalho e questão social. 2. ed. São Paulo: Cortez, 2008.

LOBO, Elizabeth Souza. A classe trabalhadora tem dois sexos: trabalho, dominação e resistência. São Paulo: Secretaria Municipal de Cultura e Brasiliense, 1991.

MARX, Karl. Trabalho assalariado e capital \& salário, preço e lucro. São Paulo: Expressão Popular, 2006.

MÉSZÁROS, Istvan. Para Além do Capital. São Paulo: Boitempo, 2011.

NOGUEIRA, Cláudia Mazzei. O trabalho duplicado: a divisão sexual do trabalho e na reprodução: um estudo das trabalhadoras do telemarketing. 1. ed. São Paulo: Expressão Popular, 2006.

PELATIERI, Patrícia; LIMA, Maria Ednalva Bezerra. Trabalho produtivo e reprodutivo: redução da jornada e fim das horas extras. In: ÁVILA, Maria Betânia et al (org.). Reflexões feministas sobre informalidade e trabalho doméstico. Recife: SOS CORPO - Instituto Feminista para a Democracia, 2008.

POSTHUMA, Anne Caroline. Mercado de trabalho e exclusão social da força de trabalho feminina. In: ABRAMO, Laís; ABREU, Alice R, de Paiva (org.). Gênero e trabalho na sociologia latino-americana. São Paulo; Rio de Janeiro: ALAST, 1998.

SAFFIOTI, Heleieth I. B. A mulher na sociedade de classes. 3. ed. São Paulo: Expressão Popular, 2013.

SAFFIOTI, Heleieth I. B. Gênero, patriarcado e violência. São Paulo: Fundação Perseu Abramo, 2004. (Coleção Brasil Urgente).

SORJ, Bila. Trabalho remunerado e trabalho não-remunerado. In: OLIVEIRA, Suely; RECANÁM, Marisol; VENTURI, Gustavo (Orgs.). A mulher brasileira nos espaços público e privado. São Paulo: Editora Fundação Perseu Abramo, 2004.

SORJ, Bila; FONTES, Adriana. O care como um regime estratificado: implicações de gênero e classe social. In: HIRATA, Helena; GUIMARÃES, Nadya Araujo (orgs.). Cuidados e cuidadoras: as várias faces do trabalho do care. São Paulo: Atlas, 2012.

TOLEDO, Cecília. Mulheres: o gênero nos une, a classe nos divide. 2. ed. São Paulo: Instituto José Luís e Rosa Sundermann, 2005.

\footnotetext{
Priscilla Brandão Medeiros

Graduada em Serviço Social pela UERN. Especialista em Docência no Ensino Superior pela UNP (Natal/RN) e em Gestão Pública da Organização em Saúde pela UFJF. Mestra em Serviço Social e Direitos Sociais pela UEPB. Doutoranda pelo PPGSS/UFRN. Participou como membro da Diretoria do Conselho Regional de Serviço Social - CRESS 14 ${ }^{\text {a }}$ Região (Gestão 2015-2017). Professora Temporária na Escola Multicampi de Ciências Médicas - EMCM/UFRN (2014/2017). É Técnica/Assistente Social no Departamento de Habitação Social e Regularização Fundiária de Caicó/RN (afastada pro doutorado).
} 